\title{
The effectiveness and cost-effectiveness of the
} Family Nurse Partnership home visiting programme for first time teenage mothers in England: a protocol for the Building Blocks randomised controlled trial

Eleri Owen-Jones ${ }^{1 *}$, Marie-Jet Bekkers ${ }^{1}$, Chris C Butler ${ }^{2}$, Rebecca Cannings-John', Sue Channon ${ }^{2}$, Kerenza Hood $^{1}$, John W Gregory ${ }^{3}$, Alison Kemp², Joyce Kenkre ${ }^{4}$, Belen Corbacho Martin ${ }^{5}$, Alan Montgomery ${ }^{6}$, Gwenllian Moody ${ }^{1}$, Kate E Pickett ${ }^{5}$, Gerry Richardson ${ }^{7}$, Zoë Roberts ${ }^{2}$, Sarah Ronaldson ${ }^{4}$, Julia Sanders ${ }^{1}$, Eugena Stamuli,

David Torgerson ${ }^{5}$ and Michael Robling ${ }^{1}$

\begin{abstract}
Background: The Nurse Family Partnership programme was developed in the USA where it is made available to pregnant young mothers in some socially deprived geographic areas. The related Family Nurse Partnership programme was introduced in England by the Department of Health in 2006 with the aim of improving outcomes for the health, wellbeing and social circumstances of young first-time mothers and their children.

Methods / design: This multi-centre individually randomised controlled trial will recruit 1600 participants from 18 Primary Care Trusts in England, United Kingdom. The trial will evaluate the effectiveness of Family Nurse Partnership programme and usual care versus usual care for nulliparous pregnant women aged 19 or under, recruited by 24 weeks gestation and followed until the child's second birthday. Data will be collected from participants at baseline, 34-36 weeks gestation, 6, 12, 18 and 24 months following birth. Routine clinical data will be collected from maternity, primary care and hospital episodes statistics. Four primary outcomes are to be reported from the trial: birth weight; prenatal tobacco use; child emergency attendances and/or admissions within two years of birth; second pregnancy within two years of first birth.
\end{abstract}

Discussion: This trial will evaluate the effectiveness and cost effectiveness of the Family Nurse Partnership in England. The findings will provide evidence on pregnancy and early childhood programme outcomes for policy makers, health professionals and potential recipients in three domains (pregnancy and birth, child health and development, and parental life course and self-sufficiency) up to the child's second birthday.

Trial registration: Trial registration number: ISRCTN23019866

Keywords: Pregnancy in adolescence, Prenatal care, Maternal health, Home visiting, Birth weight, Smoking cessation, Child maltreatment, Family nurse partnership, Early years prevention, Randomised controlled trial

\footnotetext{
* Correspondence: Owen-JonesCE@cardiff.ac.uk

${ }^{1}$ South East Wales Trials Unit (SEWTU), School of Medicine, Cardiff University, Neuadd Meirionnydd 7th Floor, Heath Park, Cardiff, Wales CF14 4YS, UK Full list of author information is available at the end of the article
} 


\section{Background}

Infants born into socioeconomic deprivation are more likely to have teenage mothers, to have been exposed to cigarette smoke during pregnancy, to have poor prenatal health profiles, and are at greater risk of adverse short-term and long-term outcomes [1-5]. In 2008 there were 44,691 live births to women under the age of 20 in England and Wales [6]. Children born to teenage mothers have lower birth weights, are less likely to be breast fed, exhibit higher mortality rates, and are more likely to suffer accidents [7]. They do worse educationally, experience more emotional and behavioural problems, and are more likely to become teenage parents themselves [8].

Over one third of infants in the UK are exposed to maternal smoking and 17\% of mothers in England continue to smoke throughout pregnancy [9-11]. Maternal smoking in pregnancy impairs fetal growth - the average difference in birth weight between infants born to smokers and to non-smokers is about 250g [12]. This difference increases with the amount smoked [13]. Smoking in pregnancy increases the risk of miscarriage, premature birth, Sudden Infant Death Syndrome (SIDS), emotional and behavioural problems, cognitive problems in childhood, adolescent criminal behaviour and adult violent and non-violent crime [14-17]. Maternal smoking is also negatively associated with breastfeeding initiation and duration [18].

Eight percent of babies born in the UK are of low birth weight compared to seven percent in France and Germany $[19,20]$. In addition to maternal smoking, risk factors for low birth weight include being a teenage mother, infection during pregnancy (causing preterm labour), family poverty and social disadvantage [21]. Consequences of having a low birth weight for gestational age or premature delivery include neurological impairment and cognitive difficulties. Adverse consequences of low birth weight on physical health and psychological distress can be found much later on in adult life [22,23].

In England, hospital and community based maternity care is provided by the National Health Service, it is universally available and free at the point of delivery. Minimum standards for maternity care are recommended by the National Institute for Clinical Excellence and include a minimum of 10 antenatal check-ups for women expecting their first baby $[24,25]$. Specific additional care is recommended for pregnant women under 20 and includes allocating a named midwife to provide the majority of the woman's care, supported by direct telephone access [26]. Health Visitors (specialist community public health nurses) provide support to new mothers and their children up to the child's fifth birthday with the level and nature of engagement depending on local resources and individual need.

Specific programmes to support the life chances of children growing up in disadvantaged circumstances have also been introduced in the United Kingdom. Sure Start Local Programmes (SSLPs) were area-based interventions for all children aged under 5 , and involved local areas improving and creating services to support young families. Whilst SSLPs changed to come under the control of local authorities and run from Children's Centres, considerable variation in delivery remained [27]. Furthermore, a more targeted programme, Sure Start Plus was piloted with the aim of reducing social exclusion associated with teenage pregnancy by providing additional community based support programmes and facilities. The pilot study of Sure Start Plus showed enhanced parenting skills, but less success in changing health damaging behaviours such as smoking [28].

The Nurse Family Partnership (NFP) programme was developed in the US to address the problems of poor birth outcomes, social exclusion, child abuse and neglect, and diminished economic self-sufficiency of socially disadvantaged younger first time mothers [29]. NFP is currently offered in 42 US states [30]. The NFP is a structured, intensive programme of home visits delivered by specially trained nurses, provided from early pregnancy until the child is two years old.

The NFP draws upon theories of human ecology, selfefficacy and human attachment [31-33]. Visits cover core content areas of personal and environmental health, life course development, maternal role, family and friends and access to health and social services. Time allocated to each content domain is prescribed by the programme but also varies over the duration of the programme. Maternal behaviour change is supported through the promotion of self-efficacy [34,35]. Education and modelling activities are included in the programme to promote sensitive and competent care giving via a strengths-based approach with the aim of reducing maltreatment. A scheduled maximum of 64 visits commence, ideally, early in the second trimester, and decrease in frequency over the first two years of the child's life. Whilst actual number of visits received may vary by individual need, engagement, and gestational age at enrolment, minimum targets are specified to support desired programme outcomes. Programme goals are to improve pregnancy outcomes, child health and development, including a reduction in child maltreatment, and an increase in maternal self-sufficiency.

In three randomised trials in the US, the NFP programme improved prenatal health behaviours, birth outcomes, sensitive child care, reductions in child injuries, abuse and neglect, maternal life course (e.g. greater workforce participation, fewer subsequent pregnancies, reduction in welfare requirements), and child and adolescent functioning $[29,36-45]$. The NFP had greatest impact amongst those with low psychological resources. The cost of the programme for low-income and unmarried mothers was recovered by the child's fourth birthday, whilst amongst married 
women or those of higher socioeconomic status a net financial saving has been demonstrated over a longer period [46].

NFP has been adapted for the UK where it is known as the Family Nurse Partnership (FNP) programme and is part of the Healthy Child Programme in England. Formal evaluation has demonstrated that FNP is deliverable and acceptable within the UK with some encouraging findings in terms of outcomes [47-49]. Although there is evidence of programme effectiveness in the US, there is no rigorous trial evidence for FNP in the UK, which has universal access to more comprehensive supportive care for young first-time mothers [24,25]. It is this evidence of short-term outcome effectiveness (up to the child's second birthday) that will be generated by the Building Blocks trial.

The trial is supported by a partnership between government, research and primary and secondary care teams. In 2008, Primary Care Trusts (PCTs) in England tendered to the Department of Health to provide the FNP programme within the study context. The successful 18 PCTs subsequently employed the FNP teams to deliver the programme. The Department of Health based FNP central team will provide FNP materials, training and ongoing support to the PCT local teams and maintain a central database of FNP activity.

FNP teams are comprised of up to eight nurses, each of whom carries a maximum caseload of 25 clients, a supervisor who carries a reduced caseload, and an administrator. This is similar to the NFP programme.

\section{Research aim}

The aims of our trial are to:

Aim 1: Evaluate the effectiveness of the FNP within three outcome domains: pregnancy and birth, child health and development, and parental life course and self-sufficiency. Four primary outcomes have been identified: birth weight, changes in prenatal tobacco use, emergency attendances and hospital admissions for the child within two years, and proportion of women with a second pregnancy within two years. Primary and secondary outcomes are listed in Tables 1 and 2 .

Aim 2: Assess the incremental costs and consequences of the FNP programme compared to existing services.

Aim 3: Model possible longer term costs and effects of the FNP programme.

Aim 4: Evaluate what processes influence FNP outcomes in order to explore applicability to other settings and to optimise its future implementation.

\section{Methods}

\section{Trial design}

This trial is an individually randomised controlled trial with a parallel economic modelling study. Trial participants either receive usual universal services or usual universal services along with regular visits from trained Family Nurses (FN) from early pregnancy (of their first child) until the child is two years old, following a prescribed programme.

\section{Intervention \\ FNP}

Participants in the intervention arm will receive up to 64 home based visits from the FNP nurse during their pregnancy and in the two years following childbirth. Fidelity requirements on programme recruitment and delivery are specified by the developers of the US programme (Table 3).

In the UK, the Family Nurse provides the FNP programme, alongside the usual maternity services during pregnancy and the neonatal period. From one month to two years after birth, the Family Nurse continues to provide the programme undertaking the role of the Health Visitor. Around the time of the child's second birthday care is handed over to a Health Visitor, whose input will vary depending upon recognised need and local resources.

Family Nurses are recruited from existing registrants on the Nursing Midwifery Council of the UK, mainly from Health Visiting but also from Nursing and Midwifery. Training in delivery of the programme will be provided to the Family Nurses by the FNP central team.

\section{Usual care}

Participants allocated to the usual care will receive care from the local maternity services in line with usual practice. Following birth, the participants will continue to receive postnatal midwifery care and care from existing child health services available locally, including an allocated Health Visitor.

\section{Site and participant selection}

Local consortia, comprising chiefly of individual Primary Care Trusts (PCTs), and local authorities formally applied to the Department of Health to be provider sites for FNP and expressed willingness to participate in the randomised trial. Each site was required to demonstrate sufficient local clinical need and collectively to yield sufficient trial recruits during the planned recruitment period.

The 18 selected trial sites are located in Barnsley, Berkshire East, Cornwall, Coventry, Cumbria, Derby, Hull, Lambeth, Leeds, Liverpool, Manchester, Northamptonshire, South Birmingham, South East Essex, Southwark, Sunderland, Tower Hamlets and Walsall. In most cases FNP will be delivered across the whole area covered by each PCT, but for some sites (e.g. Cornwall) availability of the programme will be partially restricted to certain parts of the PCT area. 
Table 1 Maternal outcomes and assessment points

\begin{tabular}{|c|c|c|c|c|c|c|}
\hline Outcome (name of measure ${ }^{1}$ ) & Baseline & $\begin{array}{l}34-36 \\
\text { weeks }\end{array}$ & $\begin{array}{l}\text { Birth } \\
\text { record }\end{array}$ & 6 months & 12 months & 18 months \\
\hline \multicolumn{7}{|l|}{ Socioeconomic } \\
\hline $\begin{array}{l}\text { Not in education, employment or training } \\
\text { (NEET status) }[50,51]\end{array}$ & $x$ & & & $x$ & $x$ & $x$ \\
\hline Hours in formal education $[50,51]$ & & & & $x$ & $x$ & $x$ \\
\hline In paid employment $[50,51]$ & $x$ & & & $x$ & $x$ & $x$ \\
\hline Type of employment [50,51] & $x$ & & & $x$ & $x$ & $x$ \\
\hline In receipt of benefits $[50,51]$ & $x$ & & & & & \\
\hline Other financial support $[50,51]$ & $x$ & & & & & \\
\hline Ever been homeless (Millennium Cohort Study) [50,51] & $x$ & & & $x$ & $x$ & $x$ \\
\hline \multicolumn{7}{|l|}{ Maternal health \& well-being } \\
\hline General health status (EQ-5D) [52] & $x$ & $x$ & & $x$ & $x$ & $x$ \\
\hline Weight / BMI (Millennium Cohort Study) [50,51] & $x$ & & & & & \\
\hline Psychological distress (Kessler scale) [53] & $x$ & & & & & \\
\hline Depression (Whooley scale) [54] & & & & $x$ & $x$ & $x$ \\
\hline Postnatal depression (Edinburgh PDS) [55] & & & & $x$ & & \\
\hline Self-efficacy (Generalised Self-efficacy Scale) [56] & $x$ & & & $x$ & $x$ & $x$ \\
\hline Adaptive functioning $[57,58]$ & $x$ & & & & & \\
\hline Intimate partner violence (Composite Abuse & & & & & & \\
\hline
\end{tabular}

\section{Health behaviour}

\section{Tobacco use $^{3}$}

Smoking cessation method (if applicable) $[60,61]$

smoke in home

Problem alcohol and drug use (CRAFFT) [62]

Contraceptive use and method (Millennium Cohort Study) [50,51]

$x$
$x$
$x$

\section{Pregnancy and birth}

Gestation at delivery

Place of birth (planned, actual)

\section{Subsequent pregnancies ${ }^{3}$}

\section{Social support}

Social support and networks (MOS Survey) [63,64]

Family resources [65]

Relationship quality (Golombok Rust Inventory of Marital State) [66]

\section{Use of services}

Dental care

Antenatal care (check-ups, planned / unplanned attendances)

Primary care or secondary care attendance / admission

Additional non-health (education, social, childrens, Connexions) services $x$

$x$

$\boldsymbol{X}$

$\begin{array}{ll}x & x \\ x & x\end{array}$

$\begin{array}{cccc} & x & x & x \\ & & & \\ x & x & x & x\end{array}$

Foster care (mother, baby, both)

$\boldsymbol{x}$

$\boldsymbol{X}$$$
\boldsymbol{X}
$$

$x$

$x$
$x$
$x$

$x$

$x$
$x$
$x$
$x$
$x$
$x$
$x$
$x$
$x$
$x$
$x$
$x$


Table 2 Parenting and child outcomes and assessment points

\begin{tabular}{|c|c|c|c|c|c|c|c|c|}
\hline Outcome (name of measure ${ }^{1}$ ) & Baseline & $\begin{array}{l}34-36 \\
\text { weeks }\end{array}$ & $\begin{array}{l}\text { Birth } \\
\text { record }\end{array}$ & 6 months & 12 months & 18 months & 24 months & $\mathrm{HES} / \mathrm{GP}^{2}$ \\
\hline \multicolumn{9}{|l|}{ Parenting beliefs, behaviour and experience } \\
\hline Anticipatory parenting (Millennium Cohort Study) $[50,51]$ & & $x$ & & & & & & \\
\hline Infant feeding intentions & & $x$ & & & & & & \\
\hline Prenatal attachment [67] & & $x$ & & & & & & \\
\hline Parental role strain (Millennium Cohort Study) $[50,51]$ & & & & $x$ & $x$ & $x$ & $x$ & \\
\hline Maternal-child interaction [68] & & & & & & & $x$ & \\
\hline Mother and child living apart & & & & $x$ & $x$ & $x$ & $x$ & \\
\hline \multicolumn{9}{|l|}{ Neonatal outcomes } \\
\hline Live birth & & & $x$ & & & & & \\
\hline Birth weight ${ }^{3}$ & & & $x$ & & & & & \\
\hline Apgar score (1,5 mins) & & & $x$ & & & & & \\
\hline Head circumference & & & $x$ & & & & & \\
\hline Neonatal unit admission & & & $x$ & & & & & \\
\hline \multicolumn{9}{|l|}{ Feeding \& development } \\
\hline Breastfeeding initiation, duration & & & & $x$ & $x$ & $x$ & $x$ & \\
\hline Baby diet & & & & & & $x$ & $x$ & \\
\hline Cognitive development [69] & & & & & $x$ & $x$ & $x$ & \\
\hline $\begin{array}{l}\text { Language development (Early Language } \\
\text { Milestone Scale) }[69,70]\end{array}$ & & & & & $x$ & $x$ & $x$ & \\
\hline Child safety [71] & & & & & $x$ & $x$ & $x$ & \\
\hline \multicolumn{9}{|l|}{ Health and use of services } \\
\hline Childcare & & & & $x$ & $x$ & $x$ & $x$ & \\
\hline Immunisations & & & & $x$ & $x$ & $x$ & & $x$ \\
\hline Emergency attendances $\&$ admissions (all cause) ${ }^{3}$ & & $x$ & & $x$ & $x$ & $x$ & $x$ & $x$ \\
\hline Primary care consultation (injuries \& ingestions) & & $x$ & & $x$ & $x$ & $x$ & & $x$ \\
\hline Medically attended injuries \& ingestions & & $x$ & & $x$ & $x$ & $x$ & $x$ & $x$ \\
\hline $\begin{array}{l}\text { Referral from primary care (social care, other, } \\
\text { safeguarding) }\end{array}$ & & & & & & & $x$ & $x$ \\
\hline
\end{tabular}

${ }^{1}$ Name of validated measure (items amended or partially sourced from existing measures indicated by citation only) ${ }^{2}$ For period from recruitment or birth until 24 months (mother and child); ${ }^{3}$ Primary outcome domain.

\section{Local researchers}

Local researchers (usually a midwife or nurse), will be employed at each trial site, and trained by the trial team prior to their site opening to recruitment and annually thereafter. Topics to be covered during the training sessions will include an overview of the trial, the FNP programme, obtaining consent and recruitment procedures. Emphasis will be placed on the assessment of the competence of potential trial participants to provide consent, explaining both arms of the trial without bias, trial outcomes, serious adverse event monitoring and reporting, and withdrawals. Later training will cover follow-up rates, retention strategies, birth related data collection, organising and conducting the 2 year home based interview, data collection from primary care records and conducting research interviews.
The role of a local researcher will be to recruit participants, maintain current contact details for participants and conduct home based interviews and assessments in their trial site. South East Wales Trials Unit, Cardiff University, in collaboration with Bristol University, University of York and University of South Wales (formerly University of Glamorgan) will implement the trial.

\section{Eligibility criteria}

Eligibility criteria will match FNP programme enrolment criteria as closely as possible and are listed in full in Table 4. Recruits will be nulliparous, aged 19 or under, and will be recruited to the trial no later than 24 weeks gestation (and ideally within the first 15 weeks). This was to enable enrolment to the FNP (for those randomised to the intervention arm) in line with the programme fidelity 
Table 3 FNP fidelity goals $[47,48,72]$

\begin{tabular}{|c|c|}
\hline FNP fidelity goals & Criteria \\
\hline \multirow[t]{5}{*}{$\begin{array}{l}\text { Recruitment and } \\
\text { enrolment }\end{array}$} & $\begin{array}{l}\text { - at least } 60 \% \text { enrolled before } 16 \text { weeks of } \\
\text { pregnancy and } 100 \% \text { no later than } 28 \text { weeks }\end{array}$ \\
\hline & - $100 \%$ of clients enrolled are first-time mothers \\
\hline & $\begin{array}{l}\text { - } 100 \% \text { of clients enrolled are } 19 \text { years or younger } \\
\text { at LMP }\end{array}$ \\
\hline & $\begin{array}{l}\text { - } 75 \% \text { of eligible clients who are offered the } \\
\text { programme are enrolled }\end{array}$ \\
\hline & $\begin{array}{l}\text { - each family nurse enrols } 25 \text { families (or pro rata) } \\
\text { within } 9 \text { months of recruitment }\end{array}$ \\
\hline \multirow[t]{6}{*}{ Attrition } & $\begin{array}{l}\text { Clients leave the programme at no more than } \\
\text { these rates: }\end{array}$ \\
\hline & $\begin{array}{l}\text { - cumulative programme attrition is } 40 \% \text { or less } \\
\text { through to the child's second birthday }\end{array}$ \\
\hline & In detail: \\
\hline & - $10 \%$ or less during the pregnancy phase \\
\hline & - $20 \%$ or less during the infancy phase \\
\hline & - $10 \%$ or less during toddlerhood \\
\hline \multirow[t]{5}{*}{ Dosage } & Clients receive: \\
\hline & $\begin{array}{l}\text { - } 80 \% \text { or more of expected visits during } \\
\text { pregnancy }\end{array}$ \\
\hline & - $65 \%$ or more of expected visits during infancy \\
\hline & $\begin{array}{l}\text { - } 60 \% \text { or more of expected visits during } \\
\text { toddlerhood }\end{array}$ \\
\hline & $\begin{array}{l}\text { On average, length of home visits is around } \\
60 \text { minutes }\end{array}$ \\
\hline
\end{tabular}

requirements $(60 \%$ of clients to be enrolled by 16 weeks gestation, and all by 28 weeks $[47,48,72])$.

\section{Recruitment}

Potential participants will be identified in conjunction with staff from antenatal clinics. Women may also either self-identify or be referred via other services including GP surgeries into the study. Referral pathways will be tailored to accommodate local variations in clinical practice pathways and services at each site. Trial information will be made available at local clinics (midwifery clinics, GP surgeries, Children's Centres, Local Connexions Offices). During the study recruitment period women in study sites will only be able to enrol in the FNP programme via participation in the trial. Direct referrals to the FNP team will be passed back to the Local Researcher to discuss trial participation.

Local Researchers will contact identified potential participants to arrange a recruitment visit where they will be provided with an information pack explaining the trial. Adequate time will be given for reading the material and asking any questions. Women will be encouraged to discuss the trial with friends and family, if needed, before deciding about participation. Informed, written consent will be obtained by the local researcher.

\section{Randomisation}

Prior to recruitment of a trial participant, the Local Researcher will confirm that the local FNP team has spare capacity, consent will be obtained and the baseline assessments completed. The Local Researchers will use a remote randomisation service (automated telephone or web) provided by Bristol Randomised Trials Collaboration (BRTC) to allocate the woman to FNP or usual care. The Local Researcher will inform the FNP team of participants allocated to receive the programme. The FNP team will then take responsibility to enrol the woman into the programme and provide the intervention. For women allocated to usual care, the woman's community midwife will be informed. All participants' General Practitioners will be notified of their recruitment to the trial.

A randomisation algorithm will minimise by gestation at recruitment ( $<16$ weeks/16 weeks +$)$, smoking status at recruitment (smoker/non-smoker) and first language/preferred language (English/non-English) for each site with a probability of 0.8 . Therefore a random element is retained, further reducing predictability of allocation. The trial statisticians and economists will be blinded to treatment allocation until analyses are complete.

Table 4 Participant inclusion/exclusion criteria

\begin{tabular}{|c|c|}
\hline Inclusion criteria & Exclusion criteria \\
\hline 1. Women aged 19 or under (at recruitment / consent). & 1. Women who at study entry, plan to have their child adopted. \\
\hline $\begin{array}{l}\text { 2. Lives within the catchment area covered by the } \\
\text { local FNP team. }\end{array}$ & $\begin{array}{l}\text { 2. Women who at study entry, plan to leave the FNP area during the time of the } \\
\text { trial either for an extended period of time ( } 3 \text { months or longer) or permanently. }\end{array}$ \\
\hline $\begin{array}{l}\text { 3. First pregnancy confirmed by health services (including those } \\
\text { expecting multiple births) unless previous pregnancy ended in } \\
\text { miscarriage, stillbirth or termination. }\end{array}$ & $\begin{array}{l}\text { 3. Women who would require a third person (translator, sign interpreter) } \\
\text { to receive the FNP programme. }\end{array}$ \\
\hline \multicolumn{2}{|l|}{ 4. Recruited no later than 24 weeks gestation. } \\
\hline $\begin{array}{l}\text { 5. Gillick competent to provide informed consent to research } \\
\text { participation including competence in English at conversational } \\
\text { level or higher. }\end{array}$ & \\
\hline
\end{tabular}




\section{Frequency and duration of follow-up to assess study outcomes}

Follow-up will continue until the child's second birthday. Following the baseline home assessment, women will be followed up by qualified and specially trained telephone interviewers at 34-36 weeks gestation, then at six months, twelve months, and eighteen months postnatally. A final home-based face-to-face interview will be conducted two years after birth. The interviewers will follow procedurespecific Standard Operating Procedures with regards to serious adverse event reporting and child safeguarding issues.

A urine sample for cotinine assessment will be collected at the baseline visit and also at 34-36 weeks gestation. Following birth, medical and obstetric history items, antenatal attendances, and maternal and neonatal birth outcomes will be extracted from medical records onto a Case Report Form. Data relating to the number, duration and content of Family Nurse visits to participants will be captured on a Department of Health database which the trial team will access. The timing and methods of data collection are summarised in Figure 1.

\section{Retention strategy}

Local researchers will be the main point of contact between the trial team and trial participants and will have a key role in maintaining participant engagement with the trial. They will update participant contact details, monitor for adverse events and promote progress of the trial. The trial team will visit sites prior to initiation, and run central training days where all the local researchers get to know one another, share best-practice procedures and be trained in how to carry out subsequent trial phases.

To maintain engagement with trial participants, based on suggestions from local stakeholders including young mothers, we will use vouchers for telephone airtime, birthday cards and presents for the baby, contacts from the local researcher, and use of SMS texting. High Street vouchers to the value of $£ 25, £ 25$ and $£ 40$ will be given after completion of the 12, 18 and 24-month interviews respectively to acknowledge their time commitment to data collection. A first year birthday gift will be sent and a second year birthday gift will be given on completion of the two year interview. Prior notification of telephone interviews will be via SMS messages to participants. A participant website will be used to encourage engagement of participants.

\section{Primary outcomes}

Four primary outcomes are to be reported from the trial (Tables 1 and 2):

- Birth weight (grams).

- Prenatal tobacco use: calibrated number of cigarettes per day at 34-36 weeks gestation [73];
- Emergency attendances and/or admissions within two years of birth: proportion of participants' children attending Accident and Emergency (A\&E) or having an emergency admission to hospital within two years of birth.

- Second pregnancy within two years of first birth: proportion of women with a subsequent pregnancy within two years of first birth.

\section{Secondary outcomes}

Secondary outcomes are shown in Tables 1 and 2. Where validated scales will be used these are named and referenced; where validated scales will be modified or items selected, these are shown with a citation only; other outcome variables will be newly derived.

\section{Sample size estimation}

A total sample of 1418 for analysis will provide at least 90\% power at the two-sided $2.5 \%$ alpha level to detect differences between the two arms of $10 \%$ (40\% to 30\%) in the proportion having any emergency attendance or emergency admission to hospital within two years, and of $7.5 \%$ (20\% to $12.5 \%)$ in the proportion with a second pregnancy within two years. For each outcome measure, the expected improvement for the FNP arm relates to a small standardised difference (approx. 0.2 or odds ratio 0.6). This small standardised difference will enable us to detect effect towards the lower end of what we expect. We will allow for a pregnancy loss of $1.5 \%$.

We expect to obtain follow-up data for three of the four primary outcomes on at least $90 \%$ of participants by accessing the medical records in hospital and primary care for both the mother and child. Follow-up smoking rates will be collected through the late pregnancy telephone interviews. We will therefore aim to recruit a total of 1600 pregnant women to achieve our target number for analysis, as this takes into account anticipated pregnancy loss and loss to follow up.

We have chosen to use a $2.5 \%$ alpha level to allow for multiple primary outcomes within each individual population in the trial - i.e. there are two primary outcomes for the mother (smoking and second pregnancy) and two for the baby (birth weight and emergency attendances/ admissions). This gives a 5\% type 1 error rate for each population.

\section{Stakeholder involvement and ethics}

A Stakeholder Involvement and Ethics Group will be responsible for working across the trial, economic and process evaluations. We recognise that pregnant teenagers are a vulnerable group, at greater risk of social exclusion (e.g. from lower socioeconomic groups, care leavers). Consequently, various sensitive and practical issues need consideration prior to study commencement, for example, 


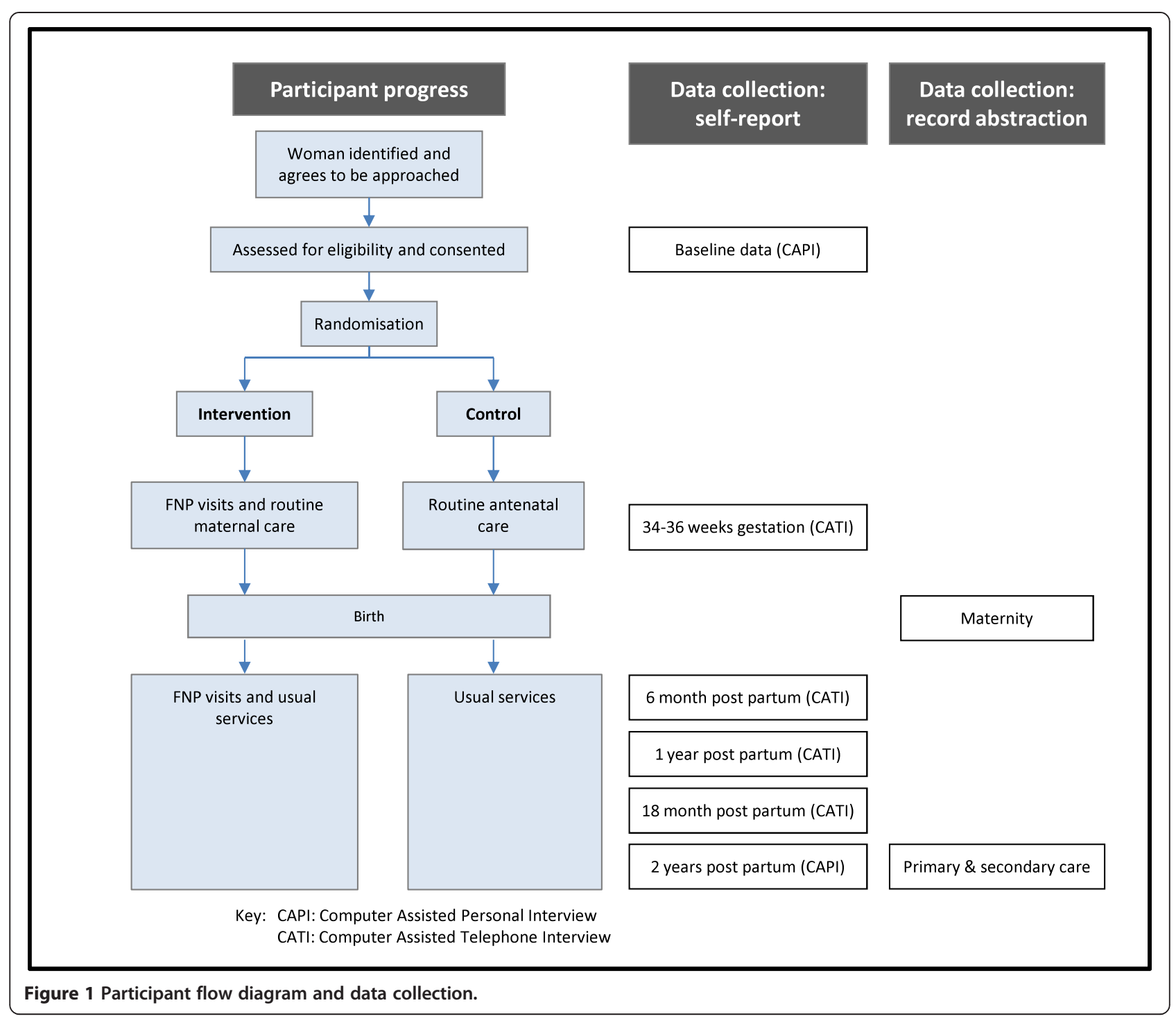

consent for those aged under 16 and procedures to be followed in the event of child safeguarding concerns. The Stakeholder Group will work to identify potential issues that may arise during the course of the trial and advise on their appropriate management. This will entail the development of a range of Stakeholder Groups to support the conduct of the trial through the various stages of development to completion.

The collaborative involvement of lay and professional people in the Stakeholder Groups will provide added value to the trial teams. Public contributors will be part of core trial management groups: Trial Steering Committee, the Stakeholder Management Group and the Independent Data Monitoring Committee. Reference groups, including young mothers, will be set up to advise on trial information materials, provide advice at the different stages of the trial, and contribute towards the design of the trial participant website.

\section{Process evaluation}

The process evaluation will aim to understand variations in the impact of the intervention and to contextualise findings [74]. Routine FNP monitoring data will be integrated with planned process evaluations using quantitative and qualitative methods [75].

\section{The process evaluation will examine}

- fidelity to programme content and style of programme delivery, and to pre-set frequency and duration targets

- participants' engagement and satisfaction with FNP

- impact of FNP roll-out as perceived by local stakeholders (FNP teams, Health Visitors, Midwives)

- wider contextual influences on programme implementation and outcomes 
Fidelity targets for FNP visits prescribe time allocation for different content domains. In the UK, delivery of the programme is integrated with Motivational Interviewing (MI) [76] which forms part of the foundation of the FNP. Fidelity assessment will include audio-recording a sample of home visits for women at each site $(n=216)$. Recordings will be assessed for consultation content and MI competencies using thematic content coding and a validated scale measuring adherence to Motivational Interviewing techniques [77]. Dose will be assessed by comparing FNP monitoring data against set performance metrics. Interviews with a sample of FNP clients $(n=72)$ will assess intervention exposure; participants in the non-intervention arm of the trial will not be interviewed. Trial recruitment and retention will be assessed by examining sample characteristics and attrition rates and predictors.

Evaluation of context will focus on mapping existing universal services using questionnaires with key informants at each site and accessing national and local policy guidelines and commissioning briefs. Planned analysis of trial outcome data will explore differential programme impact across practitioners, sites and sample sub-groups.

Further contextual factors affecting implementation and potential wider roll-out will be explored in telephone interviews with FNP supervisors and focus groups with FNP teams and other local Stakeholders (Midwives, Health Visitors). Assessing contamination will form part of the structured telephone interviews with local stakeholders and the focus group discussions.

\section{Health economics and modelling}

Intervention effects will extend beyond the health sector, both within the timeframe of the trial and in the future. Therefore two components of work are required: one to explore the relative value of effects within the different sectors (health, social care, education, criminal justice) and another to consider the longer term extrapolation of trial results (i.e. over the lifetime of the child). To inform both of these, a literature review of economic outcomes within criminal justice and education literature will be conducted.

Valuation of effects: preference elicitation work will be undertaken in order to measure the relative values that members of the general public place on the different outcomes of the trial. Specifically, a discrete choice experiment and a best-worst scaling exercise will be conducted. This work will consider the trade-offs that people are prepared to make between benefits in the different sectors, which will inform the relative magnitude of benefits accruing to different sectors.

Economic extrapolation: the extrapolation exercise will seek to link the primary outcomes of the trial with longer term outcomes in health, education, employment and criminality extending to the childhood and adulthood of the index baby, and the mother. A literature review will be conducted to capture studies that examine the association between the short term primary outcomes, as measured in the trial, and the longer term outcomes. The inclusion of the studies will be done in stages, where cohort studies of longitudinal nature that enrolled participants at birth stage or prenatally and were conducted in the UK will be prioritised. The results of the literature review will be summarized in a narrative way and all the links will be presented in a tabulated format. The results of the review will be interpreted in light of the FNP trial results.

\section{Statistical analysis}

\section{Main analysis - primary outcomes}

The primary comparative analyses will be conducted on an intention-to-treat basis, with an emphasis placed on confidence intervals for differences between the randomised arms.

Descriptive statistics of demographic and outcome measures will be used to ascertain any marked imbalance between the arms at baseline. For birth weight and prenatal tobacco use at 34-36 weeks the primary comparative analyses will employ multivariable linear regression to investigate differences between the arms, adjusting for stratification/ minimisation variables. In the case of prenatal tobacco use the calibrated number of cigarettes per day reported at baseline will also be adjusted for. The result will be presented as the (adjusted) difference in mean number of cigarettes per day between the intervention and control arms. Parameter estimates will be shown alongside 95\% confidence intervals (CIs) and p-values.

For the proportion of children with at least one emergency attendance and/or admission and proportion of women with known subsequent pregnancies, logistic regression will be used adjusting for stratification/minimisation variables. Comparisons will be presented as odds ratios, 95\% CIs and p-values.

Multilevel modelling will be used to allow for clustering of effect within a site and Family Nurse. Where this analysis indicates little impact of clustering on effect then the results from the single level model will be presented. Sensitivity analyses will be conducted to investigate the potential impact of missing data, making different assumptions such as 'best' and 'worst' case scenarios as well as imputation models. Where variables exhibit marked imbalance at baseline, primary analyses will be repeated and adjustments will be made to check that this does not influence findings. The same analyses will be carried out for the secondary outcomes depending on the type of data.

Appropriate interaction terms will be entered into the primary regression analyses for each of the outcomes in 
order to conduct pre-specified subgroup analyses. These subgroups will be defined by the Trial Management Group in advance of any analysis being started with input from the trial team and summaries of current evidence from the literature. Since the trial is powered to detect overall differences between the arms rather than interactions of this kind, the results of these exploratory analyses will be presented using confidence intervals as well as p-values.

Routine data on compliance with the FNP and usual maternity and early childhood services will be collected and utilised in understanding any outcome differences between the two arms.

\section{Process evaluation analysis}

To establish internal validity, a sample of audio-recorded pregnancy, infancy, and toddlerhood home visits will be compared for self-reported and independently established programme content, using descriptive statistics. Similarly, a sample of FNP practitioners will be examined on the MI specific competency of their programme delivery using the Motivational Interviewing Treatment Integrity (MITI) validated scale ratings [77]. Dose and structure of visits will be monitored and compared to pre-set targets. Recruitment and retention to the trial will be monitored on an ongoing basis. Contamination between trial arms will be established using descriptive statistics from the service mapping survey and follow-up trial questionnaires. The full trial data set will be subjected to subgroup analyses to determine potential environment influences on implementation and outcomes.

\section{Cost effectiveness/health economics analysis Costs}

For the primary analysis, the resource use data related to health care services utilised by the trial participants such as GP visits, hospital overnight stays, accident and emergency attendances will be considered. These data will be collected for both intervention and control arm from self-reported questionnaires, the NHS Hospital Episode Statistics and patient records held at GP practices. For the secondary analyses, in addition to the health care resource usage, non-health care costs will be included. These relate to services such as social assistance, housing, education and criminal justice. The data for this type of resource usage will be collected from the self-reported questionnaires.

The cost of the intervention will be assessed based on the routine data collected by the FNP nurses and input into the central Department of Health FNP database. This includes information directly related to the FNP utilisation such as the number and percentage of completed visits by the FNP nurses as well as their duration, and the number of telephone encounters with the client. In addition, the database includes information on the qualifications of the FNP nurses which will be used to assess the remuneration bracket of the nurses for the overall costing of this service.

\section{Outcomes}

For the economic analysis, the same primary outcomes that have been considered in the statistical analysis will be used. These will be analysed and reported as outcomes in a cost-consequences analysis or, wherever this is appropriate, in a cost-effectiveness analysis. Where data allow, these effectiveness estimates will be linked to utility scores and a cost-utility analysis will be conducted. A cost-utility analysis will be used for estimating the impact of the programme on maternal health. The outcome for this analysis is measured by calculating quality-adjusted life years (QALYs). Direct estimation of QALYs is not possible for children as they will be too young during the trial, but we will estimate the intervention impact upon the mothers using the EQ-5D. The cost-utility analysis will be based on the QALYs difference of the mothers between the two arms from 34-36 weeks gestation of the index child and up to the second birthday of that child, when the trial is completed.

\section{Unit costs}

Unit cost estimates will be applied to resource use data to generate individual level cost estimates. Sources of unit costs will include routine or published literature such as the latest Personal Social Services Research Unit (PSSRU) Unit Costs of Health and Social Care [78] and the latest NHS Reference Costs [79]. In addition, published sources and information from local health care providers will be sought. For the non-health related resources, unit costs will be sought from the relevant sources such as governmental websites.

\section{Data analysis and presentation of the results}

Two types of analyses will be conducted: a complete case analysis (CCA) and an analysis by using multiple imputation methods; both analyses will include allowance for the clustered nature of the data. In the 'complete case analysis' only trial participants with available total costs and primary outcomes will be included. In the multiple imputation analysis all participants with partial information on resource usage and outcomes will be included. Missing values will be imputed by using multiple imputation (MI) methods. A range of sensitivity analyses will be conducted to test the robustness of the results under different scenarios. These scenarios will capture variability in the estimates of cost and outcomes, which result from either different methods (e.g. imputation methods) or from different sources of data (e.g. unit cost data).

Incremental cost-effectiveness ratios (ICERs) will be calculated where appropriate. These demonstrate the mean 
difference in costs and effect between treatment strategies, i.e. the incremental cost per QALY gained will be presented. The mean differences in costs and effects between the two arms of the trial will be estimated by using a regression based approach (allowing for covariate adjustment and subgroup analyses) and the 95\% confidence intervals around those will be estimated by using bias corrected and accelerated bootstrapped methods. Cost effectiveness acceptability curves (CEACs) will be generated through the use of probabilistic sensitivity analysis. The CEAC will plot the probability of the intervention being cost-effective for a range of threshold values of an additional QALY.

\section{Ethical and governance approval}

Multi-centre approval has been granted by the Research Ethics Committee for Wales (ref. no. 09/MRE09/8). Site-specific approval has been granted at all participating Primary Care and Acute Trusts.

\section{Adverse event monitoring}

We will apply a procedure for the monitoring and reporting of serious adverse events (SAEs). These will be reported to the trial team by the local researchers, telephone interviewers and any other member of the local clinical team. Given the anticipated high number of pregnancy related hospital attendances and admissions, SAEs will be further assessed to identify those that are clinically complex or serious.

\section{Discussion}

The aim of the trial is to determine whether there are important, significant differences in maternal and child outcomes during pregnancy, at birth and until the child's second birthday between pregnant teenagers who are offered FNP and to those offered usual care in England.

Whilst there is evidence for the effectiveness of NFP from the US before the child's second birthday, the main benefits of the NFP programme have been seen later in childhood. Therefore lack of overall programme impact cannot be concluded if this trial finds a lack of effect in the pregnancy and birth domain.

Although increased birth weight is not a direct aim of FNP, there may be an impact if rates of smoking and other lifestyle factors are influenced by the programme. Due to the clinical importance of birth weight and the availability of reliable data this has been included as a primary outcome for the child. A planned subgroup analysis of birth weight will be undertaken for mothers who smoke at baseline.

The Building Blocks randomised controlled trial has been designed to estimate impacts on outcomes occurring amongst recipients of FNP compared to routine care. As benefits of the FNP can accrue following completion of the programme, the trial includes measures which could be predictive of longer-term outcomes. At the two-year follow-up assessment (at the end of the trial), further permission will be sought to contact the trial participants to enable longer term follow-up beyond the end of the current trial period.

This trial provides an example of an evaluation of government policy. This inevitably requires management of complex interactions between a government department delivering the policy, local providers of services, locally employed researchers and university based academics. With 18 trial sites covering urban and rural settings and each with unique service provision and populations, the trial team will be required to adapt procedures and pathways to meet local need, and preserve intervention fidelity whilst maintaining the integrity of the randomised trial.

The challenges in the delivery of this trial will be complex and many. In addition to the coordination required to maintain engagement in 18 PCT sites spread across major cities and some rural areas in England, the trial will also need to engage staff groups employed by 23 NHS Trusts that provide hospital based maternity care. Specific challenges related to trial setup include the recruitment and appointment of 18 locally NHS employed researchers and the identification of suitable but flexible recruitment pathways. Participants will be active in the trial for over 2 years during which time many are expected to several change their address and other contact details. To overcome such challenges, inevitable in this trial design, an age appropriate, comprehensive retention strategy will be developed, alongside usual intensive trial management procedures.

\section{Abbreviations \\ A\&E: Accident and emergency; CCA: Complete case analysis; CEACs: Cost effectiveness acceptability curves; Cls: Confidence intervals; FN: Family nurse; FNP: Family nurse partnership; ICER: Incremental cost-effectiveness ratio; MI: Multiple imputation; MI: Motivational interviewing; MITI: Motivational interviewing treatment integrity; NFP: Nurse family partnership; NHS: National health service; PCT: Primary care trusts; PSSRU: Personal social services research unit; SAE: Serious adverse event; SIDS: Sudden infant death syndrome; SMS: Short message service; SSLPS: Sure start local programmes; QALYS: Quality-adjusted life years.}

\section{Competing interests}

The authors declare that they have no competing interests.

\section{Authors' contributions}

MR is chief investigator of the trial. MR, KH, CCB, JG, AK, JK, JS,

$A M, K P, D T$ and $G R$ are responsible for the design of the trial and senior trial management. EOJ, JS and GM are responsible for trial coordination, supervision and data management. RCJ, AM and ZR are responsible for statistical planning and for data analysis. MJB and SC are responsible for the process evaluation. JK was responsible for the stakeholder work. GR, ES, BCM, DT and SR are responsible for the health economics. All authors read and approved the final manuscript.

\section{Acknowledgements}

Participating local centres (in alphabetical order) Barnsley, Berkshire East, Cornwall, Coventry, Cumbria, Derby City, Hull, Lambeth, Leeds, Liverpool, Manchester, Northampton, South Birmingham, South East Essex, Southwark, Sunderland, Tower Hamlets and Walsall. 
Thank you to Katy Addison and Jackie Swain for all their administrative help Thank you to the R\&D manager Kelly Hard at the lead R\&D site at Birmingham Women's NHS Foundation Trust.

The South East Wales Trials Unit is funded by the National Institute for Health and Social Care.

This is an independent report commissioned and funded by the Policy Research Programme in the Department of Health. The views expressed are not necessarily those of the Department.

\section{Author details}

'South East Wales Trials Unit (SEWTU), School of Medicine, Cardiff University, Neuadd Meirionnydd 7th Floor, Heath Park, Cardiff, Wales CF14 4YS, UK ${ }^{2}$ Cochrane Institute of Primary Care and Public Health, School of Medicine, Cardiff University, Heath Park, Cardiff, Wales CF14 4YS, UK. ${ }^{3}$ Institute of Molecular and Experimental Medicine, Cardiff University, Heath Park, Cardiff, Wales CF14 4XW, UK. ${ }^{4}$ University of South Wales, Pontypridd, Wales CF37 1DL, UK. ${ }^{5}$ Department of Health Sciences, University of York, Seebohm Rowntree Building, Heslington, York YO10 5DD, UK. ${ }^{6}$ Nottingham Clinical Trials Unit, Nottingham Health Science Partners, C Floor, South Block, Queen's Medical Centre, Nottingham NG7 2UH, UK. ${ }^{7}$ Centre for Health Economics, University of York, Heslington, York YO10 5DD, UK.

Received: 12 July 2013 Accepted: 22 July 2013

Published: 6 August 2013

\section{References}

1. Kuh D, Hardy R, Langenberg C, Richards M, Wadsworth MEJ: Mortality in adults aged 26-54 years related to socioeconomic conditions in childhood and adulthood: post war birth cohort study. Br Med J 2002, 325(7372):1076-1080.

2. Power C, Matthews S: Origins of health inequalities in a national population sample. Lancet 1997, 350(9091):1584-1589.

3. Lissau I, Sorensen TIA: Parental neglect during childhood and increased risk of obesity in young adulthood. Lancet 1994, 343(8893):324-327.

4. Galobardes B, Lynch JW, Smith GD: Childhood socioeconomic circumstances and cause-specific mortality in adulthood: systematic review and interpretation. Epidemiol Rev 2004, 26:7-21.

5. Evans GW, English K: The environment of poverty: multiple stressor exposure, psychophysiological stress, and socioemotional adjustment. Child Dev 2002, 73(4):1238-1248.

6. Office for National Statistics: Review of the National Statistician on births and patterns of family building in England and Wales, Correction Notices Birth Statistics 2008. Newport: ONS; 2010. FM1(37): 1-79.

7. Botting B, Rosato M, Wood R: Teenage mothers and the health of their children. Popul Trends 1998, 93:19-28

8. Moffitt TE: Teen-aged mothers in contemporary Britain. J Child Psychol Psychiatry 2002, 43(6):727-742.

9. Ward C, Lewis S, Coleman T: Prevalence of maternal smoking and environmental tobacci smoke exposure during pregnancy and impact on birth weight: retrospective study using Millenium Cohort. BMC Publ Health 2007, 7(81). doi:10.1186/1471-2458-7-81.

10. NHS Information Centre: Statistics on smoking: England, 2006. Leeds: NHS 13/HSCIC; 2006:1-146.

11. Graham H, Inskip HM, Francis B, Harman J: Pathways of disadvantage and smoking careers: evidence and policy implications. J Epidemiol Community Health 2006, 60(2):ii7-ii12.

12. The US Department of Health and Human Services: 2004 Surgeon General's Report - The Health Consequences of Smoking. Atlanta: Centers for Disease Control and Prevention; 2004:1-903.

13. Nabet C, Ancel P-Y, Burguet A, Kaminski M: Smoking during pregnancy and preterm birth according to obsteric history: French national perinatal surveys. Paediatr Perinat Epidemiol 2005, 19(2):88-96.

14. Wakschlag WS, Lahey BB, Loeber R, Green SM, Gordon RA, Leventhal BL: Maternal smoking during pregnancy and the risk of conduct disorder in boys. Arch Gen Psychiatry 1997, 54(7):670-676.

15. Wakschlag LS, Pickett KE, Cook E, Benowitz NL, Leventhal BL: Maternal smoking during pregnancy and severe antisocial behavior in offspring: a review. Am J Public Health 2002, 92(6):966-974.

16. Button TMM, Maughan B, McGuffin P: The relationship of maternal smoking to psychological problems in the offspring. Early Hum Dev 2007, 83(11):727-732.
17. Julvez J, Ribas-Fito N, Torrent M, Forns M, Garcia-Esteban R, Sunyer J: Maternal smoking habits and cognitive development of children at age 4 years in a population-based birth cohort. Int J Epidemiol 2007, 36(4):825-832.

18. Horta BL, Victoria CG, Menezes AM, Barros FC: Environmental tobacco smoke and breastfeeding duration. Am J Epidemiol 1997, 146(2):128-133.

19. United Nations Children's Fund and World Health Organisation: Low birthweight: country, regional and global estimates. New York: UNICEF; 2004:1-31.

20. World Health Organization: Reproductive health indicators database. Geneva: World Health Organization; 2006.

21. Roberts EM: Neighborhood Social Environments and the Distribution of Low Birthwieght in Chicago. Am J Public Health 1997, 87(4):597-603.

22. Wiles NJ, Peters TJ, Leon DA, Lewis G: Birth weight and psychological distress at age 45-51 years Results from the Aberdeen Children of the 1950s cohort study. Br J Psychiatry 2005, 187:21-28.

23. Barker DJP: Fetal origins of cardiovascular disease. Ann Med 1999, 31(1):3-6.

24. NICE: Antenatal Care: NICE clinical guideline 62. Manchester: National Institute for Health and Clinical Excellence; 2008.

25. NICE: Routine postnatal care of women and their babies: NICE clinical guideline 37. Manchester: National Institute for Health and Clinical Excellence; 2006.

26. National Collaborating Centre for Women's and Children's Health: Pregnancy and complex social factors:A model for service provision for pregnant women with complex social factors. London: Royal College of Obstetricians and Gynaecologists; 2010:1-321

27. Melhuish E, Belsky J, Barnes J: Evaluation and the value of Sure Start. Arch Dis Child 2010, 95:159-161.

28. Wiggins M, Rosato M, Austerberry H, Sawtell M, Oliver S: Sure Start Plus National Evaluation: Final Report. London: Social Science Research Unit, Institute of Education, University of London; 2005:1-110.

29. Olds DL: Prenatal and infancy home visiting by nurses: from randomized trials to community replication. Prev Sci 2002, 3(3):153-172.

30. Nurse-Family Partnership: National Snapshot - Nurse Family Partnership. Denver, CO: NFP National Service Office; 2013:1.

31. Bronfenbrenner U: The ecology of human development: experiments by nature and design. Boston, MA: Harvard University Press; 1979.

32. Bandura A: Self-efficacy: toward a unifying theory of behavioural change. Psychol Rev 1977, 84(2):191-215

33. Bowlby J: Attachment and Loss, vol. 1: Attachment. New York: Basic Books; 1982.

34. Rollnick S, Miller WR, Butler CC: Motivational Interviewing In Healthcare. New York: Guildford Press; 2008.

35. Miller WR, Rollnick S: Motivational Interviewing: Preparing People for Change. 2nd edition. New York: Guildford Press; 2002

36. Olds D, Henderson CRJ, Cole R, Eckenrode J, Kitzman H, Luckey D, Pettitt L, Sidora K, Morris P, Powers J: Long-term effects of nurse home visitation on behavior - 15-year follow-up of a randomized controlled trial. JAMA 1998, 280(14):1238-1244.

37. Olds D, Henderson CRJ, Kitzman H, Cole R: Effects of Prenatal and Infancy Nurse Home Visitation on Surveillance of Child Maltreatment. Pediatrics 1995, 95(3):365-372

38. Olds DL, Henderson CRJ, Chamberlin R, Tatelbaum R: Preventing child abuse and neglect: a randomized trial of nurse home visitation. Pediatrics 1986, 78(1):65-78.

39. Olds DL, Henderson CRJ, Kitzman H: Does prenatal and infancy home visitation have enduring effects on qualities of parental caregiving and child health at 25 to 50 months of life? Pediatrics 1994, 93(1):89-98,

40. Olds DL, Henderson CRJ, Tatelbaum R, Chamberlin R: Improving the delivery of prenatal care and outcomes of pregnancy: a randomized trial of nurse home visitation. Pediatrics 1986, 77(1):16-28.

41. Olds DL, Henderson CRJ, Tatelbaum R, Chamberlin R: Improving the life-course development of socially disadvantaged mothers: a randomized trial of nurse home visitation. Am J Public Health 1988, 78(11):1436-1445.

42. Olds DL, Kitzman H, Cole R, Robinson J, Sidora K, Luckey DW, Henderson CRJ, Hanks C, Bondy J, Holmberg J: Effects of nurse home-visiting on maternal life course and child development: age 6 follow-up results of a randomized trial. Pediatrics 2004, 114(6):1550-1559.

43. Olds DL, Kitzman H, Hanks C, Cole R, Anson E, Sidora-Arcoleo K, Luckey DW, Henderson CRJ, Holmberg J, Tutt RA, et al: Effects of nurse home visiting on maternal and child functioning: age 9 follow-up of a randomized trial. Pediatrics 2006, 120(4):832-845. 
44. Olds DL, Robinson J, O'Brien R, Luckey D, Pettitt LM, Henderson CRJ, Ng RK, Sheff KL, Korfmacher J, Hiatt S, et al: Home visiting by paraprofessionals and by nurses: a randomized, controlled trial. Pediatrics 2002, 110(3):486-496.

45. Olds DL, Robinson J, Pettitt L, Luckey DW, Holmberg J, Ng RK, Isacks K, Sheff K, Henderson CRJ: Effects of home visits by paraprofessionals and by nurses: age 4 follow-up results of a randomized trial. Pediatrics 2004, 114(6):1560-1568

46. Karoly LA, Greenwood PW, Everingham SS, Hoube J, Kilburn RM, Rydell CP, Sanders M, Chiesa J: Investing in Our Children: What we know and don't know about the costs and benefits of early childhood interventions. Santa Monica: The RAND Corporation; 1998.

47. Barnes J, Ball M, Meadows P, McLeish J, Belsky J, Team FIR: Nurse-Family Partnership Programme: First Year Pilot Sites Implementation in England Pregnancy and the Post-partum Period. London: Birkbeck, University of London; 2008.

48. Barnes J, Ball M, Meadows P, Belsky J, Team FIR: Nurse-Family Partnership Programme: Second Year Pilot Sites Implementation in England - The Infancy Period. London: Birkbeck, University of London; 2009.

49. Ball M, Barnes J, Meadows P: Issues emerging from the first 10 pilot sites implementing the Nurse-Family Partnership home-visiting programme in England. London: Birkbeck, University of London; 2012.

50. Calderwood L, Ward K, other members of the Millennium Cohort Team: Millennium Cohort Study First Survey: Derived Variables. London: Centre for Longitudinal Studies, Bedford Group for Lifecourse \& Statistical Studies, Institute of Education, University of London; 2004.

51. NatCen: Millennium Cohort Study First Survey: CAPI Questionnaire Documentation. London: Institute of Education, University of London; 2003.

52. EQ-5D Website. [http://www.eurogol.org/].

53. Kessler RC, Andrews G, Colpe LJ, Hiripi E, Mroczek DK, Normand SLT, Walters EE, Zaslavsky AM: Short screening scales to monitor population prevalences and trends in non-specific psychological distress. Psychol Med 2002, 32(6):959-976

54. Whooley MA, Avins AL, Miranda J, Browner WS: Case-finding instruments for depression - two questions are as good as many. J Gen Intern Med 1997, 12(7):439-445.

55. Cox JL, Holden JM, Sagovsky R: Detection of postnatal depression development of the 10-item edinburgh postnatal depression scale. Br J Psychiatry 1987, 150:782-786.

56. The General Self-Efficacy Scale. [http://userpage.fu-berlin.de/ health/selfscal.htm]

57. Booth CL, Mitchell SK, Barnard KE, Sieker SJ: Development of Maternal Social Skills in Multiproblem Families: Effects on the Mother-Child Relationship. Dev Psychol 1989, 25(3):403-412.

58. Barnard K, Hilsinger G, Patteson D, Snyder C, Solchany J, Shangle M: Washington State Public Health Training Plan: Improving Child-Family Health. Parent Protective Factors Project (1995-1999) Final Report July, 1999. Washington: US Department of Health; 1999.

59. Hegarty K: Composite Abuse Scale Manual. Melbourne: Department of General Practice, University of Melbourne; 2007.

60. Wakschlag LS, Pickett KE, Middlecamp MK, Walton LL, Tenzer P, Leventhal BL: Pregnant smokers who quit, pregnant smokers who don't: does history of problem behavior make a difference? Soc Sci Med 2003, 56(12):2449-2460

61. Heatherton TF, Kozlowski LT, Frecker RC, Fagerstrom KO: The fagerstrom test for nicotine dependence - a revision of the fagerstrom tolerance questionnaire. Br J Addict 1991, 86(9):1119-1127.

62. Knight JR, Sherritt L, Shrier LA, Harris SK, Chang G: Validity of the CRAFFT substance abuse screening test among adolescent clinic patients. Arch Pediatr Adolesc Med 2002, 156(6):607-614.

63. Hays RD, Sherbourne CD, Mazel RM: User's Manual for the Medical Outcomes Study (MOS) Core Measures of Health-Related Quality of Life. Santa Monica, CA: Rand; 1995.

64. Sherbourne CD, Stewart AL: The MOS social support survey. Soc Sci Med 1991, 32(6):705-714

65. Dunst CJ, Leet HE: Measuring the adequacy of resources in households with young children. Child Care Health Dev 1987, 13(2):111-125.

66. Rust J, Bennun I, Crowe M, Golombok S: The GRIMS. A psychometric instrument for the assessment of marital discord. J Fam Ther 1990 12(1):45-57.

67. Muller ME: A questionnaire to measure mother-to-infant attachment. J Nurs Meas 1994, 2(2):129-141.
68. Crittenden PM: CARE-Index: Coding Manual. Unpublished manuscript. Miami, FL: available from the author; 1979 - 2004.

69. Bellman M, Lingam S, Aukett A: Schedule of Growing Skills II (SOGS II). 2nd edition. London: GL Assessment Limited; 1996.

70. Coplan J, Gleason JR, Ryan R, Burke MG, Williams ML: Validation of an early language milestone scale in a high-risk population. Pediatrics 1982 , 70(5):677-683.

71. Holtby S, Zahnd E, Lordi N, McCain C, Chia YJ, Kurata J: Health of California's Adults, Adolescents and Children: Findings from CHIS 2003 and CHIS 2001. LOS Angeles, CA: UCLA Center for Health Policy Research; 2006.

72. Barnes J, Ball M, Meadows P, Howden B, Jackson A, Henderson J, Niven L: The Family-Nurse Partnership Programme in England: Wave 1 implementation in toddlerhood \& a comparison between Waves 1 and 2a of implementation in pregnancy and infancy. In London: Institute for the Study of Children, Families and Social Issues. Birkbeck: University of London; 2011:127.

73. Dukic VM, Niessner M, Benowitz N, Hans S, Wakschlag L: Modeling the relationship of cotinine and self-reported measures of maternal smoking during pregnancy: a deterministic approach. Nicotine Tob Res 2007 , 9(4):453-465.

74. Oakley A, Strange V, Bonell C, Allen E, Stephenson J: Process evaluation in randomised controlled trials of complex interventions. BMJ 2006, 322(7538):413-416.

75. Saunders RP, Evans MH, Joshi P: Developing a process evaluation plan for assessing health promotion program implementation: a how-to guide. Health Promot Pract 2005, 6(2):134-147.

76. Rollnick S, Miller WR: What is motivational interviewing? Behav Cogn Psychother 1995, 23:325-334.

77. Moyers TB, Martin T, Manuel JK, Miller WR, Ernst D: Revised Global Scales: Motivational Interviewing Treatment Integrity 3.1.1 (MITI 3.1.1). Albuquerque, NM: University of New Mexico, Center on Alcoholism, Substance Abuse and Addictions (CASAA); 2010.

78. Curtis L: Unit Costs of Health \& Social Care 2011. Canterbury: Personal Social Services Research Unit; 2011.

79. 2010-11 reference costs publication: [https://www.gov.uk/government/ publications/2010-11-reference-costs-publication]

doi:10.1186/1471-2431-13-114

Cite this article as: Owen-Jones et al:: The effectiveness and costeffectiveness of the Family Nurse Partnership home visiting programme for first time teenage mothers in England: a protocol for the Building Blocks randomised controlled trial. BMC Pediatrics 2013 13:114.

\section{Submit your next manuscript to BioMed Central and take full advantage of:}

- Convenient online submission

- Thorough peer review

- No space constraints or color figure charges

- Immediate publication on acceptance

- Inclusion in PubMed, CAS, Scopus and Google Scholar

- Research which is freely available for redistribution

Submit your manuscript at www.biomedcentral.com/submit
C) Biomed Central 